This is the final peer-reviewed accepted manuscript of:

Armorini, Sara, Alberto Altafini, Anna Zaghini, e Paola Roncada. 2016. «Ochratoxin A in artisan salami produced in Veneto (Italy)». Food Additives \& Contaminants: Part B 9 (1): 9-14.

The final published version is available online at: https://doi.org/10.1080/19393210.2015.1098735

Rights / License:

The terms and conditions for the reuse of this version of the manuscript are specified in the publishing policy. For all terms of use and more information see the publisher's website.

This item was downloaded from IRIS Università di Bologna (https://cris.unibo.it/)

When citing, please refer to the published version. 


\section{Ochratoxin A in artisan salami produced in Veneto (Italy)}

Sara Armorini, Alberto Altafini, Anna Zaghini, Paola Roncada

Department of Veterinary Medical Sciences, University of Bologna, via Tolara di Sopra 50, 40064

4 Ozzano Emilia (BO), Italy.

5 Paola Roncada (corresponding author) Department of Veterinary Medical Sciences, University of 6 Bologna, via Tolara di Sopra 50, 40064 Ozzano Emilia (BO), Italy. Tel. +390512097511 Fax $7 \quad+39051799511$

$8 \quad$ E-mail address: paola.roncada@unibo.it

9

\section{ABSTRACT}

Fifty samples of artisan salami purchased in Veneto (Italy) were analysed for the determination of ochratoxin A (OTA). The analytical method, based on a sample preparation procedure with immunoaffinity columns (IACs), together with analysis by high-performance liquid chromatography with fluorescence detection (HPLC-FD), has guaranteed a high rate of recovery (about 97\%), limit of detection (LOD) and limit of quantification (LOQ), respectively, of $0.06 \mu \mathrm{g} \mathrm{kg}^{-1}$ and $0.20 \mu \mathrm{g} \mathrm{kg}^{-1}$. OTA was detected in five samples, but only one exceeded the guideline value $\left(1 \mu \mathrm{g} \mathrm{kg}^{-1}\right)$ established by the Italian Ministry of Health for pork meat and derived products. The results would seem to suggest that salami made with the traditional, non-industrial production method can be considered safe as regards contamination by OTA. However, the very high concentration observed in one sample proves that a high OTA contamination is also possible in this type of product. Thus, the controls of mycotoxin contamination must consider also salami.

KEYWORDS: Mycotoxins, ochratoxin A, salami, HPLC, immunoaffinity, fluorescence detection

\section{Introduction}

Salami (Salame in Italian) is a typical product of the Italian sausage tradition. Salami is defined as a charcuterie product, consisting of meat obtained from striated muscles belonging to pig carcase with the addition of sea salt and eventually meat of other animal species, minced and combined in varying proportions with pork fat, and packed into natural or artificial casings (Ministero delle Attività Produttive 2005). The meat is allowed to ferment before being packed into casings and then hung up 
to cure. The curing process activates bacteria, which makes the ground meat an inhospitable environment for dangerous bacteria that can cause meat to spoil. In this way, the product is safe to eat, without refrigeration, for several years. The long shelf life is one of the reasons why such products were so popular before the development of the modern refrigeration systems. Salami is a generic term indicating a large group of meat products. Each Italian region produces specific types of salami that can differ on the basis of various criteria: the origin of the meat, the methods of chopping and preparation of the lean and the fatty parts (which can be chopped fine, coarse or into little cubes), the ratio between the different parts, the salting and the addition of different spices, the type of casing, the size of the final product, the development of moulds on the casing and the seasoning methods. The production of salami is often linked with local customs and traditions and represents a real cultural heritage; several consortiums have been established for the protection of these products and to obtain the recognition of them as Protected Designation of Origin (PDO) or Protected Geographical Indication (PGI) product.

Ochratoxins are mycotoxins produced by various Aspergillus and Penicillium spp., particularly Penicillium verrucosum and Aspergillus ochraceus (Kuiper-Goodman \& Scott 1989). They are widely spread in the world, reaching a high level of contamination, especially in some countries of Northern Europe and South America (Devegowda et al. 1998). These ubiquitous saprophytic moulds can contaminate grains, feed and food; they develop during the crop growth, but also during the storage phase. The ochratoxin-producing fungi, for the growth in cereals, require a minimum moisture content of $17-18 \%$ and temperatures of $8-37^{\circ} \mathrm{C}$. The genus Aspergillus, more commonly associated with warmer climates, prefers food products with high fat and protein content like sausages, while Penicillium is the typical storage mould and it grows in cool temperate climates, preferring cereals rich in carbohydrates such as barley and wheat (Sweeney \& Dobson 1998; Magan \& Aldred 2005; Cicoňova et al. 2010). There are three ochratoxin compounds, ochratoxin A (OTA), ochratoxin B (OTB) and ochratoxin C (OTC); OTA is the most common one and contaminates various types of food of plant origin as well as some animal products such as liver and kidney. In terms of toxicity, OTA and OTC are the most dangerous, while OTB has toxicity values 10 times lower than that of OTA (Marquardt \& Frohlich 1992). OTA is a very stable and persistent molecule and it is responsible for many carcinogenic, nephrotoxic, immunotoxic, teratogenic, neurotoxic and genotoxic effects on laboratory and farm animals. OTA is classified as possibly carcinogenic to humans (IARC 1993).

Regarding the main sources of human exposure to OTA, a survey carried out at the European level shows that cereals are the primary source of contamination $(50 \%)$ by OTA. Other matrices affected by contamination are wine (13\%), coffee (10\%), spices (8\%), beer (5\%), cocoa (4\%), dried fruit (3\%) and meat (1\%) (European Commission 2002; Jørgensen 2005). The Commission of the European 
Communities fixed maximum levels in several foodstuffs (European Commission 2006a). It is important to remember that OTA may be present in animal feed, but meat, milk and eggs from animals fed with contaminated feeds have so far been considered a negligible source for human exposure. However, higher concentrations of OTA may be present in certain local specialties such as blood puddings and sausages prepared with pig blood serum (EFSA 2006). Between farm animals, the pig is known to be particularly sensitive to OTA, which can be found in decreasing concentration in kidneys, then liver and muscles (Curtui et al. 2001; Malagutti et al. 2005) and fat (Krogh et al. 1976; Madsen et al. 1982). The Commission of European Communities fixed, in Recommendation 2006/576/EC, a guidance value for OTA of $0.05 \mathrm{mg} / \mathrm{kg}$ in complementary and complete feeding stuff for pigs (European Commission 2006b), but didn't set maximum OTA levels in meat-based products. However, in Italy, since 1999 the Ministry of Health has established a guideline OTA value of $1 \mu \mathrm{g}$ $\mathrm{kg}^{-1}$ in pork meat and derived products (Ministero della Sanità 1999).

The aim of this study was to carry out a monitoring action to assess the presence of OTA in artisan salami sampled in Veneto (Italy), using a suitable analytical method for the evaluation of OTA in highly heterogeneous meat products such as salami. In the Veneto region, there is a long tradition in the production of handmade salami from small family-run farms and holiday farms. Since these small farms have no self-control systems like the major meat product factories, it becomes interesting to assess whether OTA, in these small productions, constitutes a real risk to human health.

\section{Material and methods}

\section{Salami samples}

From September to October 2013, 50 different salamis were purchased in a random manner from family-run farms, holiday farms and mountain huts ("malghe") located in Veneto, in the provinces of Vicenza and Treviso. In particular, the samples were 14 fresh salamis, five aged salamis and 31 soprèssa (typical Venetian salami). After purchase, the samples were registered and catalogued in the laboratory notebook. From each salami, three 100 grams aliquots (cross sections) were sampled in different positions and collected after removing the casing; the aliquots were minced together using a mini grinder (Illico, Moulinex, France) and stored at $-20^{\circ} \mathrm{C}$ until analysis.

\section{Solvents and reagents}

The chemicals and solvents used for the extraction of OTA from salami samples (ethyl acetate, phosphoric acid, sodium bicarbonate), as well as the chemicals used to prepare PBS buffer (sodium chloride, disodium hydrogen phosphate anhydrous, potassium phosphate monobasic, potassium chloride) were ACS grade (Carlo Erba Reagents, Cornaredo, MI, Italy). The solvents used in the post- 
extraction immunoaffinity clean-up (water, methyl alcohol), and all solvents used for HPLC analysis (water, acetonitrile, isopropyl alcohol, acetic acid), were HPLC grade (Mallinckrodt Baker B.V., Deventer, The Netherlands). OTA standard was purchased from Sigma-Aldrich Co. (St Louis, MO, USA). Immunoaffinity columns (IACs) used for sample purification (OchraTest ${ }^{\mathrm{TM}} \mathrm{WB}$ ) were purchased from Vicam ${ }^{\circledR}$ (Milford, MA, USA).

\section{Chromatographic apparatus}

The HPLC system consisted of a System Gold Programmable Solvent Module 126 pump (Beckman Coulter, Brea, CA, USA) equipped with an HT 800 L autosampler (HTA, Brescia, Italy) fitted with a $20 \mu 1$ loop and a 821 FP fluorescence detector (Jasco, Tokyo, Japan); fluorescence excitation and emission wavelengths were 340 and $460 \mathrm{~nm}$ respectively. The system was computer-controlled by a Beckman Coulter 32 Karat Software. The HPLC column was a C18 Onyx Monolithic column 100 $\mathrm{mm} \times 4.6 \mathrm{~mm}$ (Phenomenex, Torrance, CA, USA) coupled in sequence to a C18 Chromolith Performance RP-18e column 100 mm x 4.6 mm (Merck, Darmstad, Germany). Chromatographic separation was achieved in gradient conditions and at room temperature. The mobile phase consisted of water-acetonitrile-isopropyl alcohol-acetic acid $1 \%$ mixtures in various ratios. Mobile phase A: water/acetonitrile/isopropyl alcohol/acetic acid 1\% (79:7:7:7 v/v) and mobile phase B: acetonitrile. Gradient: from $80 \% \mathrm{~A}$ and $20 \% \mathrm{~B}$ to $58 \% \mathrm{~A}$ and $42 \%$ B in 11 min with linear increase. Flow rate: 1 $\mathrm{ml} / \mathrm{min}$. The injection volume was $20 \mu \mathrm{l}$.

\section{Sample extraction}

The extraction of OTA from salami was carried out following the methods described by Monaci et al. (2004), (2005) and Bozzo et al. (2012) with some modifications. A $2.5 \mathrm{~g}$ aliquot of minced sample was acidified with $1.5 \mathrm{ml}$ of $1 \mathrm{M}$ phosphoric acid and homogenised in $5 \mathrm{ml}$ of ethyl acetate for $3 \mathrm{~min}$ using an Ultra-Turrax homogeniser. The sample was centrifuged for $3 \mathrm{~min}$ (1900 xg) and the upper organic phase was transferred into a $15 \mathrm{ml}$ conical centrifuge tube. The pellet was then extracted a second time in the same manner, and after centrifugation, the second organic phase was removed and combined with the first one. The combined extract, after being frozen $\left(-20^{\circ} \mathrm{C}\right)$ for $3-4$ hours, was centrifuged for $10 \mathrm{~min}(1900 \mathrm{xg})$ in order to separate emulsified and suspended components, which were removed. An $8 \mathrm{ml}$ aliquot of the extract (equivalent to $2 \mathrm{~g}$ sample) was then exactly measured into a $10 \mathrm{ml}$ graduated glass centrifuge tube and reduced to $2 \mathrm{ml}$ with a Univapo rotational vacuum concentrator (Uniequip, Martinsried/Munich, Germany). The organic extract was back-extracted by adding $2 \mathrm{ml}$ of $0.5 \mathrm{M}$ sodium bicarbonate solution: the tube containing the two solvents was thoroughly mixed for $30 \mathrm{~min}$ on a rotating shaker, frozen $\left(-20^{\circ} \mathrm{C}\right)$ for one hour and centrifuged for 
$10 \min (1900 \mathrm{xg})$. Finally, the organic phase was removed and the bicarbonate extract was subjected to clean-up.

\section{Sample clean-up}

An aliquot of $1.5 \mathrm{ml}$ of bicarbonate extract was diluted with $3.5 \mathrm{ml}$ of PBS buffer and loaded onto an OchraTest $^{\mathrm{TM}}$ WB IAC. The column was then washed with $10 \mathrm{ml}$ of PBS buffer and $10 \mathrm{ml}$ of water; finally, OTA was eluted with $1.5 \mathrm{ml}$ of methanol. The eluate was reduced to dryness by means of Univapo and the residue redissolved in $150 \mu \mathrm{l}$ of methanol, diluted with $150 \mu \mathrm{l}$ of water, and after vortexing, injected into HPLC.

\section{Quantification}

The parameters considered for the validation of the analytical method for the HPLC-FD detection of OTA in salami were linearity and range, specificity, accuracy and precision, limit of detection (LOD), limit of quantification (LOQ) and recovery. The evaluation of linearity and range was performed by analysing five calibration standards of OTA in the range $0.2-2 \mu \mathrm{g} \mathrm{kg}^{-1}$, prepared from blank samples spiked directly with OTA standard solutions. Specificity, related to the absence of interfering substances under the experimental conditions, was determined by calculating the mean values $( \pm$ standard deviation) of the retention time of OTA present in spiked samples and in unknown samples. Accuracy and precision were evaluated via the analysis of spiked samples, using nine determinations over three concentration levels in the range $0.2-2 \mu \mathrm{g} \mathrm{kg}^{-1}$ (three concentrations/three replicates each). Accuracy was expressed as the deviation of the mean from the true value, and precision as the relative standard deviation (RSD) of the replicate measurements. The LOQ of the method was the lowest concentration of the calibration curves of OTA. The LOD was established on the basis of a signal-tonoise ratio of 3 at OTA retention time. The recovery was obtained by analysing pre-spiked extracted samples in the range $0.2-2 \mu \mathrm{g} \mathrm{kg}^{-1}$ compared with the detector response obtained for pure OTA standard solutions at the same concentration levels. For its evaluation, at least three concentration levels/three replicates each were used. For internal quality control purposes the unknown samples processed the same day were always accompanied by one or more spiked blank samples. This study was performed according to ISO 9001 (2008) requirements. Also, a z-score of -1.40 for OTA in durum wheat at a level of $12.45 \mu \mathrm{g} \mathrm{kg}^{-1}$ was obtained in a proficiency test (Bacer 2012).

\section{Results and discussion}

\section{Assay validation}


159 In the considered concentration range $\left(0.2-2 \mu \mathrm{g} \mathrm{kg}^{-1}\right)$, the calibration curves of OTA were linear $160\left(\mathrm{R}^{2}>0.999\right)$. The specificity of the method was acceptable. No interfering peaks were observed in 161 the spiked samples and no significant peaks were found within the retention time window of OTA in 162 the non-contaminated samples. Retention time for OTA was $14.09 \pm 0.09$ minutes. This value was 163 stable $(\mathrm{RSD}=0.64 \%$ over 4 days). The run time was 16 minutes. Figure 1 shows the chromatograms 164 of a blank sample (A) and a naturally contaminated sample at $0.44 \mu \mathrm{g} \mathrm{kg}^{-1}$ (B). Three calibration 165 standards at concentrations of $0.4,1.0$ and $1.5 \mu \mathrm{g} \mathrm{kg}^{-1}$ were prepared and analysed at three different days. The RSD for each concentration assayed never exceeded 3\%. LOD and LOQ of the method were $0.06 \mu \mathrm{g} \mathrm{kg}^{-1}$ and $0.20 \mu \mathrm{g} \mathrm{kg}^{-1}$, respectively, and were far below the guideline value of $1 \mu \mathrm{g} \mathrm{kg}^{-1}$ established by the Italian Ministry of Health. Recovery rates were checked in three concentrations and the overall average was $97.4 \%$. For each concentration, three measurements were performed and the RSDs ranged from 2.7 to $4.7 \%$ (Table 1). Since salami is a complex matrix and a nonhomogeneous material, it was critical to ensure the representativeness of the test sample that was obtained by homogenisation of three sample aliquots taken at different points of each salami. The clean-up method using IACs is fast, takes less than $15 \mathrm{~min}$, and this made it possible to obtain analytical samples without interfering substances in the chromatogram. Moreover, the gradient developed for conducting HPLC analysis and the use of monolithic columns allowed good analytical results.

\section{OTA in salami samples}

In this study 50 salami samples were analysed and five of them (10\%) were positive for OTA (Table 2). Two of these positive samples showed very low OTA concentrations, just above the LOD. Another two positive samples showed concentrations slightly above the LOQ. Only in one sample the OTA concentration exceeded the guidance value of $1 \mu \mathrm{g} \mathrm{kg}^{-1}$ as established by the Italian Ministry of Health (Ministero della Sanità 1999). Given the very high concentration of this sample, for its quantification, it has been properly diluted before HPLC analysis. Examining the data of this study on the occurrence of OTA in salami, some considerations can be made. The percentage of positive samples and the low concentration, below the guidance value of $1 \mu \mathrm{g} \mathrm{kg}^{-1}$ for OTA in meat, found in four out of five samples, suggests that artisan salami is a safe food regarding the presence of OTA. On the other hand, the very high concentration observed in one sample (number sample-id 17) was a value more than 100 times higher than the guidance value. This leads to the conclusion that a high contamination by OTA is also possible in this type of product. The external appearance of this sample was normal, without damages of casing; the shape was cylindrical, and regularly bound with colourless twine. Also, the appearance on cutting was normal, and no existence of cracks was 
underscored. Finally, the organoleptic characteristics (particular smell and flavour) were very good and no signs of spoilage were found. This salami deserves further comment about the possible cause of its contamination and about the causes of OTA contamination of salami in general. It is also conceivable that a similar amount of OTA might be the result of a combination of several adverse events. First, consideration should be given to the presence of OTA in muscle and fat of pigs used for the production of the contaminated soprèssa, due to the assumption of contaminated feed. In this regard, the scientific literature reports several experiments in which tissues of various organs from pigs exposed to OTA-contaminated feed were analysed (Krogh et al. 1976; Raja et al. 2008). Other studies also considered final products prepared from pork meat. A recent article (Perši et al. 2014) reports data on OTA concentration in meat sausages produced from raw materials coming from pigs exposed to OTA-contaminated feed ( $300 \mu \mathrm{g}$ OTA $/ \mathrm{kg}$ feed) for 30 days. The results pointed out that a sub-chronic pig exposure leads to the accumulation of OTA in raw materials and consequently in meat products, whose level of contamination is directly dependent on OTA contents in raw materials used for their production.

An experiment conducted on growing pigs fed with OTA $25 \mu \mathrm{g} \mathrm{kg}^{-1}$ contaminated feed for 119 days was reported by Malagutti et al. (2005). The pork meat was taken to make seasoned sausage and analyses were carried out to determine OTA in fresh sausages after 40 and 100 days of seasoning. Despite the OTA concentration in feed being below the limit established by current regulations (50 $\mu \mathrm{g} \mathrm{kg}^{-1}$ ), the final OTA content in meat was much higher than the Italian guideline value of $1 \mu \mathrm{g}$ $\mathrm{kg}^{-1}$. Seasoning and storage do not seem to have any effect on the reduction of OTA levels in meat products (Malagutti et al. 2005). However, if feed-associated intoxication was the only cause, the level of contamination detected in sample 17 is so high that it would be reasonable to assume that OTA concentrations in feed might have caused symptoms of ochratoxicosis in pigs. On the other hand, several authors report that indirect transmission of OTA from animals exposed to contaminated feed to pork products occurs rarely (Pietri et al. 2006; Iacumin et al. 2009). Some studies show that the extent of the contamination would be largely dependent on the environmental conditions typical of ageing and the characteristics of the production plant. If good manufacturing practices are not followed, or mistakes occur in the control of the relative humidity and temperature of the drying and ripening rooms, a significant growth of slime consisting of various moulds is often observed (Iacumin et al. 2009). A study carried out to assess the mycoflora in ham-manufacturing plants reports the constant presence of Aspergilli and Penicillia, potential mycotoxin producers, isolated from the air and the ham in all checked plants (Battilani et al. 2007). Another study reports that during the ripening process, a number of moulds colonise dry-cured sausages; temperature and salt content (which affects water activity, aw) predispose the surface to colonisation by Penicillium species, including 
Penicillium nordicum and Penicillium verrucosum, which can lead to OTA contamination of the sausages (Rodríguez et al. 2015). A study conducted at two Spanish dry-cured ham manufacturing plants showed that the genus Penicillium represents the majority of the surface mycobiota of drycured hams. It was also the predominant fungal genus in environmental samples, indicating that fungal colonisation of dry-cured hams might be determined by fungi present in the environment of ripening rooms. It also showed that a certain percentage of fungal strains $(9.5 \%)$ belonging to different Penicillium species was able to produce OTA (Alapont et al. 2014).

Additional possible sources of contamination are two ingredients normally used in the preparation of salami: spices and red wine. The most utilised spices are garlic, anise, cinnamon, cloves, coriander, fennel, nutmeg and pepper. Among these, OTA was reported as a natural contaminant in pepper and nutmeg. However, the levels of mycotoxins in spices are generally low when compared with other food products. Sometimes salami producers proceed with the addition of local wine, which further characterises the harmony of different and pleasant flavours of typical Venetian salami. Wine brings aromas and perfumes and plays an antiseptic and colour fixative action due to the sulphur dioxide contained in it. On the other hand, wine is also considered, after cereals, one of the primary sources of contamination by OTA. In fact, in a study at the European level also involving Italy, the percentage of contaminated wine samples was very high (59.3\%), and considering only data for Italy, the percentage is even higher $(80.6 \%)$. The levels of contamination ranged from $0.003 \mu \mathrm{g} \mathrm{kg}^{-1}$ (Spain) to $15.60 \mu \mathrm{g} \mathrm{kg}^{-1}$ (Italy). Among the different types, red and sweet wines seem to be the most contaminated (European Commission 2002). However, considering the low amount of spices and wine in salami, it is unlikely that these ingredients cause high OTA contamination in the final product.

\section{Conclusion}

The analytical method, based on a sample preparation procedure with IACs, together with analysis by HPLC-FD, is reliable for the determination of OTA in meat products like salami. This preliminary study that considered a relatively low number of samples suggests that salami made with the traditional, non-industrial production method, as regards OTA contamination, can be considered safe. The very high concentration observed in one sample proves that a high contamination by OTA is also possible in this type of product. Therefore, mycotoxin controls in food should also consider salami, as well as other pig meat products, although these seem less at risk for this type of intoxication when compared with cereals and other products of plant origin. It would be interesting to extend research to salami producers in other areas.

\section{Disclosure statement}


No potential conflict of interest was reported by the authors.

\section{References}

Alapont C, López-Mendoza MC, Gil JV, Martínez-Culebras PV. 2014. Mycobiota and toxigenic Penicillium species on two Spanish dry-cured ham manufacturing plants. Food Addit Contam. Part A. 31:93-104.

Bacer V. 2012. Progetto Trieste 2012, 1st round - Mycotoxins, Final report [Internet], Proficiency Testing Service by Test Veritas S.r.l [cited 2012 Sep 19]. Padova. Available from: http://www.testveritas.com/it/proficiency-testing-progetto-trieste/

Battilani P, Pietri A, Giorni P, Formenti S, Bertuzzi T, Toscani T, Virgili R, Kozakiewicz Z. 2007. Penicillium populations in dry-cured ham manufacturing plants. J Food Prot. 70:975-980.

Bozzo G, Ceci E, Bonerba E, Di Pinto A, Tantillo G, De Giglio E. 2012. Occurrence of Ochratoxin A in the Wild Boar (Sus scrofa): chemical and Histological Analysis. Toxins. 4:1440-1450.

Cicoňova P, Laciakova A, Mate D. 2010. Prevention of ochratoxin A contamination of food and ochratoxin A detoxification by microorganisms - a review. Czech J Food Sci. 28:465-474.

Curtui VG, Gareis M, Usleber E, Märtlbauer E. 2001. Survey of Romanian slaughtered pigs for the occurrence of mycotoxins ochratoxins A and B, and zearalenone. Food Addit Contam. Part A. 18:730-738.

Devegowda GM, Raju VLN, Swamy HVLN. 1998. Mycotoxins: novel solutions for their counteraction. Feedstuffs. 70:12-16.

European Commission. 2002. SCOOP task 3.2.7. Assessment of dietary intake of Ochratoxin A by the population in EU Member States [Internet; cited 2002 Jan]. Available from: ec.europa.eu/food/fs/scoop/index_en.html

European Commission. 2006a. Commission Regulation (EC) N. 1881/2006 of 19 December 2006 setting maximum levels for certain contaminants in foodstuffs. Off J Eur Union L. 364:5-24.

European Commission. 2006b. Commission Recommendation of 17 August 2006 on the presence of deoxynivalenol, zearalenone, ochratoxin A, T-2 and HT-2 and fumonisins in products intended for animal feeding (Text with EEA relevance) (2006/576/EC). Off J Eur Union L. 229:7-9.

European Food Safety Authority. 2006. Opinion of the Scientific Panel on Contaminants in the Food Chain on a request from the Commission related to ochratoxin A in food, adopted on 4 April 2006. Efsa J. 365:1-56. 
Iacumin L, Chiesa L, Boscolo D, Manzano M, Cantoni C, Orlic S, Comi G. 2009. Moulds and ochratoxin A on surfaces of artisanal and industrial dry sausages. Food Microbiol. 26:65-70.

IARC. 1993. Some naturally occurring substances: food items and constituents, Heterocyclic Aromatic Amines and Mycotoxins. IARC Monogr Eval Carcinog Risks Hum. 56:489-521.

ISO 9001. 2008. International Standard ISO 9001:2008. Quality management systems requirements. Geneva: International Organization for Stardardization.

Jørgensen K. 2005. Occurrence of ochratoxin A in commodities and processed food - a review of EU occurrence data. Food Addit Contam. 22;S1:26-30.

Krogh P, Elling F, Hald B, Larsen AE, Lillehoj EB, Madsen A, Mortensen HP. 1976. Timedependent disappearance of ochratoxin A residues in tissues of bacon pigs. Toxicology. 6:235-242.

Kuiper-Goodman T, Scott PM. 1989. Risk assessment of the mycotoxin ochratoxin. Biomed Environ Sci. 2:179-248.

Madsen A, Hald B, Lillehøj E, Mortensen HP. 1982. Feeding experiments with ochratoxin A contaminated barley for bacon pigs. Acta Agr Scand. 32:369-372.

Magan N, Aldred A. 2005. Conditions of formation of ochratoxin A in drying, transport and in different commodities. Food Addit Contam. 1:10-16.

Malagutti L, Zannotti M, Scampini A, Sciaraffia F. 2005. Effects of Ochratoxin A on heavy pig production. Anim Res. 54:179-184.

Marquardt RR, Frohlich AA. 1992. A review of recent advances in understanding ochratoxicosis. J Anim Sci. 70:3968-3988.

Ministero della Sanità. 1999. CIRCOLARE 9 giugno 1999, n.10 Direttive in materia di controllo ufficiale sui prodotti alimentari: valori massimi ammissibili di micotossine nelle derrate alimentari di origine nazionale, comunitaria e Paesi terzi. Roma (Italy): Istituto Poligrafico dello Stato Ed. Gazzetta Ufficiale n. 135 del 11-06-1999.

Ministero delle Attività Produttive. 2005. DECRETO 21 Settembre 2005 Disciplina della produzione e della vendita di taluni prodotti di salumeria. Roma (Italy): Istituto Poligrafico dello Stato Ed. Gazzetta Ufficiale n. 231 del 4-10-2005.

Monaci L, Palmisano F, Matrella R, Tantillo G. 2005. Determination of ochratoxin A at part-pertrillion level in Italian salami by immunoaffinity clean-up and high-performance liquid chromatography with fluorescence detection. J Chromatogr A. 1090:184-187. 
318 Monaci L, Tantillo G, Palmisano F. 2004. Determination of ochratoxin A in pig tissues by liquid319 liquid extraction and clean-up and high-performance liquid chromatography. Anal Bioanal Chem. $320 \quad 378: 1777-1782$.

321 Perši N, Pleadin J, Kovačević D, Scortichini G, Milone S. 2014. Ochratoxin A in raw materials 322 and cooked meat products made from OTA-treated pigs. Meat Sci. 96:203-210.

323 Pietri A, Bertuzzi T, Gualla A, Piva G. 2006. Occurrence of ochratoxin A in raw ham muscles and 324 in pork products from northern Italy. Ital J Food Sci. 1:1-8.

325 Raja AV, Saikumar G, Rinku S, Dwivedi P. 2008. Ochratoxicosis in Swine: clinical and 326 pathological changes following prolonged exposure to Ochratoxin A. Indian J Anim Sci. 78:922327928.

328 Rodríguez A, Capela D, Medina Á, Córdoba JJ, Magana N. 2015. Relationship between 329 ecophysiological factors, growth and ochratoxin A contamination of dry-cured sausage based 330 matrices. Int J Food Microbiol. 194:71-77.

331 Sweeney MJ, Dobson ADW. 1998. Mycotoxin production by Aspergillus, Fusarium and 332 Penicillium. Int J Food Microbiol. 43:141-158.

333 Figure 1. Chromatograms obtained on IAC purified extracts of (A) salami blank sample, and (B) 334 salami naturally contaminated with OTA at $0.44 \mu \mathrm{g} \mathrm{kg}^{-1}$. 

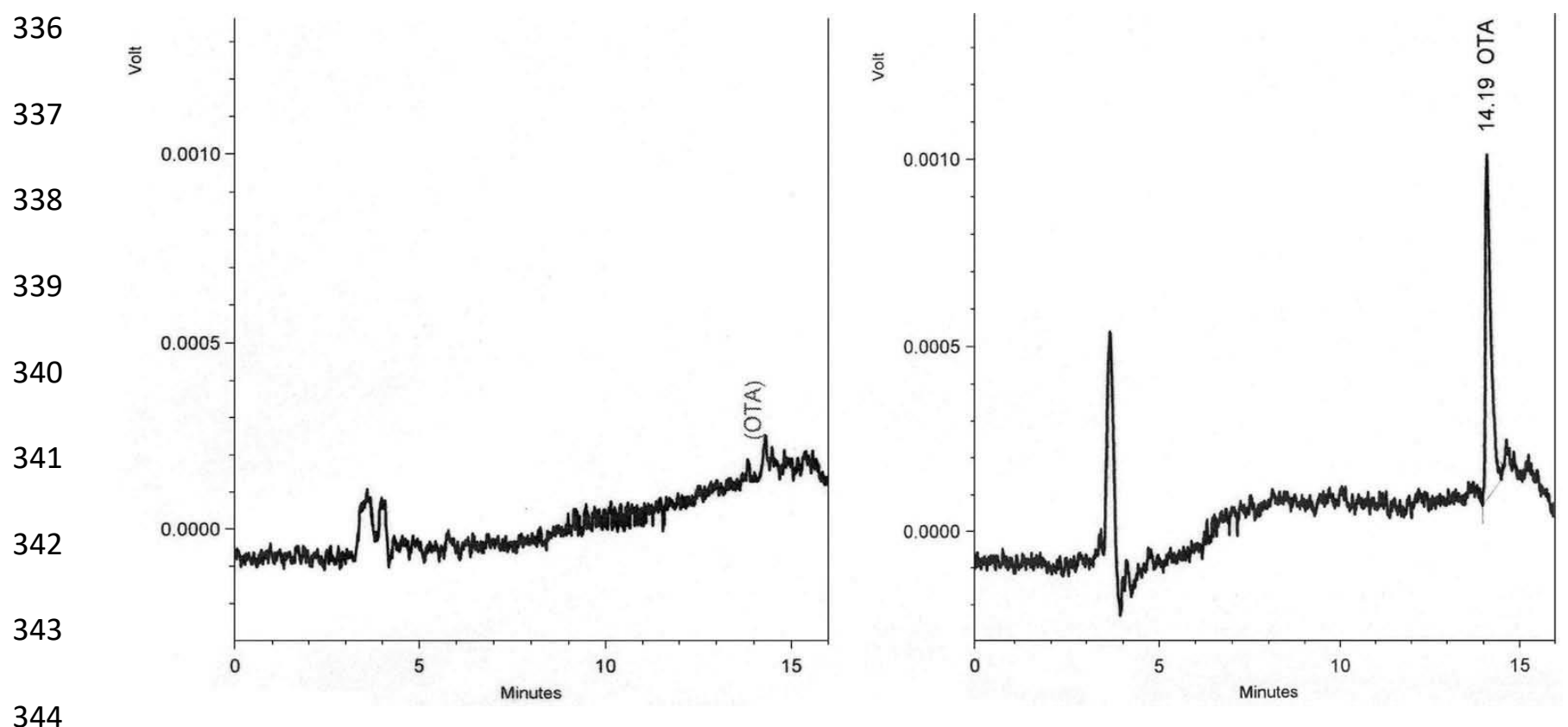

Table 1. Recovery and precision of the HPLC-FD method for OTA analysis in salami, as determined in triplicate.

\begin{tabular}{|l|l|l||}
\hline Spike & Recovery & RSD \\
\hline \hline $\mathrm{g} \mathrm{kg}^{-1}$ & $\%$ & $\%$ \\
\hline 0.4 & 97.0 & 2.7 \\
\hline 1.0 & 99.5 & 4.7 \\
\hline 1.5 & 95.7 & 3.7 \\
\hline
\end{tabular}

345

\begin{tabular}{|c|c|c|}
\hline Sample id. & Type & $\mu \mathrm{g} \mathrm{kg}^{-1}$ \\
\hline 9 & Soprèssa & 0.09 \\
\hline 12 & Soprèssa & 0.44 \\
\hline 17 & Soprèssa & 103.69 \\
\hline 31 & Soprèssa & 0.06 \\
\hline 32 & Soprèssa & 0.28 \\
\hline
\end{tabular}

